\title{
The course of lung function in treated tropical pulmonary eosinophilia
}

\author{
S. C. $\mathrm{POH}$ \\ Tan Tock Seng Hospital, Singapore 11
}

\begin{abstract}
Poh, S. C. (1974). Thorax, 29, 710-712. The course of lung function in treated tropical pulmonary eosinophilia. A follow-up study over a period of two years in the lung function of 15 patients with tropical pulmonary eosinophilia successfully treated with diethylcarbamazine is reported. A return to normal of the lung function with the exception of the transfer factor and forced expiratory volume is observed by the end of six months and these abnormalities persist up to the end of the study. The possible pathological causes of this defect are discussed.
\end{abstract}

Studies of pulmonary function in tropical pulmonary eosinophilia have recently been described (Udwadia, 1967; Azad Khan, Patra, Banu, and Rabbee, 1970; Nesarajah, 1972; Poh, 1973). A restrictive pattern has been found in all patients, about $30 \%$ showing airway obstruction as well. Little is known of the course of the lung pathology and function following effective therapy with diethylcarbamazine. Symptomatic relief is obtained and a haematological response occurs within two weeks of starting therapy together with an improvement in the radiological appearances of the chest. However, biopsies of the lung in two patients by Udwadia and Joshi (1964) have shown extensive eosinophilic infiltration even after a month of therapy with diethylcarbamazine although complete relief of symptoms had occurred after seven days' therapy.

In view of the possibility that permanent damage to the lung may result even after successful symptomatic treatment, a study was made to assess the pulmonary function over a period of two years in patients with tropical pulmonary eosinophilia seen consecutively and treated at the Tan Tock Seng Hospital, Singapore.

\section{MATERIALS AND METHODS}

Only patients who fulfilled the following criteria were selected:

(1) a history of paroxysmal cough, worse at nights, with or without expectoration;

(2) a peripheral blood eosinophil count of over $3,000 / \mathrm{mm}^{3}$

(3) radiographic changes showing increased bronchovascular markings or diffuse mottling;
(4) a clinical and haematological response to therapye with diethylcarbamazine.

Patients who gave a past history of chest disease or previous treatment for tropical pulmonary eosinoo philia were excluded.

The lung function measurements consisted of test of ventilatory capacity, measurements of static lungू volumes (using the helium closed-circuit method fo $\mathbb{2}$ measurement of the functional residual capacity), and resting transfer factor by the steady-state end-tida? sampling method. Blood gas analyses were performed with the Astrup apparatus and a reflection oximeter The predicted normal values are from data obtained. in the same laboratory and published previously (Poh, and Chia, 1969), together with unpublished data for the transfer factor.

Tests of pulmonary function were carried out before் starting treatment and were repeated a fortnight late? and at the third, sixth, twelfth, eighteenth, an 8 twenty-fourth months. Diethylcarbamazine was given to all the patients in a dosage of $18 \mathrm{mg} / \mathrm{kg}$ per dayb divided into three equal doses for one week, followed by $100 \mathrm{mg}$ three times daily for another week. Alf the patients responded to treatment. There were no relapses nor recurrences of tropical pulmonary eosinoN philia. Of the initial 24 patients, 15 have been followed up for two years and their results form the basis of this report.

\section{RESULTS}

As previously described (Poh, 1973), all the 240 patients had a restrictive pattern of lung function, seven showing a superimposed reversible airwayo obstruction as revealed by a ratio of forced expiratory volume in one second to forced vital capacitys $\left(\mathrm{FEV}_{1} / \mathrm{FVC}\right)$ of less than $70 \%$. Six of the sever迎 patients with both an obstructive and restrictive 
pattern and nine with only a restrictive pattern have been followed up for a period of two years. The observed data for the 15 patients as a whole are compared with the predicted value. No account has been taken of the slight fall in certain predicted values with age as this fall is considered to have little effect on the overall results.

The six patients with obstruction as well as restriction were initially hypoxaemic with a mean oxygen saturation of $93.4 \%$ and a mean $\mathrm{FEV}_{1} / \mathrm{FVC}$ ratio of $58.3 \%$. When tested at the end of two weeks the mean oxygen saturation and mean $\mathrm{FEV}_{1} / \mathrm{FVC}$ ratio had returned to normal values (Table I). The arterial oxygen saturation in the nine patients without obstruction was normal (mean value $96.4 \%$, range $95-98 \%$ ) befcre treatment and was not repeated at the end of two weeks.

The progress in the lung function of the 15
T A B L E I

MEAN VALUES OF FEV $/$ /FVC AND OXYGEN SATURATION FOR THE SIX PATIENTS

\begin{tabular}{l|c|c}
\hline & Pretreatment & At 2 Weeks \\
\hline FEV 1 FVC $\%$ & $58 \cdot 3$ & $\mathbf{8 4 \cdot 0}$ \\
& $(45-69)$ & $(72-92)$ \\
O, saturation $\%$ & 93.4 & 96.8 \\
& $(91-96)$ & $(96-98)$ \\
\hline
\end{tabular}

patients is shown in Tables II and III. By the sixth month all the parameters had returned to normal with the exception of the forced expiratory volume and transfer factor. The same abnormalities are present at the end of two years.

The Figure shows the progress of the mean vital capacity, forced expiratory volume, and transfer factor expressed as a percentage of the predicted values for the period of the study.

T A B L E I I

MEAN VALUES (AND STANDARD DEVIATIONS) FOR PREDICTED NORMAL AND PATIENTS

\begin{tabular}{|c|c|c|c|c|c|c|c|c|}
\hline & \multirow[b]{2}{*}{ No. } & \multicolumn{7}{|c|}{ Lung Function Measurements } \\
\hline & & $\begin{array}{l}\text { VC } \\
\text { (1.) }\end{array}$ & $\begin{array}{l}\text { FRC } \\
\text { (1.) }\end{array}$ & $\begin{array}{l}\text { RV } \\
\text { (1.) }\end{array}$ & $\underset{(1 .)}{\text { TLC }}$ & $\underset{(1 . / \mathrm{sec})}{\text { MMFR }}$ & $\underset{(1 . / \mathrm{min})}{\mathrm{FEV}_{0.75}} \times 40$ & $\frac{\mathrm{TF}}{(\mathrm{ml} / \mathrm{min} / \mathrm{mmHg}}$ \\
\hline Predicted normal & 15 & $\begin{array}{r}3.46 \\
(0.81)\end{array}$ & $\begin{array}{c}2.85 \\
(0.74)\end{array}$ & $\begin{array}{c}1.43 \\
(0.53)\end{array}$ & $\begin{array}{c}4.80 \\
(0.88)\end{array}$ & $\begin{array}{c}4 \cdot 04 \\
(0 \cdot 78)\end{array}$ & $\begin{array}{c}111 \cdot 33 \\
(4 \cdot 45)\end{array}$ & $\begin{array}{l}20.46 \\
(2.03)\end{array}$ \\
\hline \multirow[t]{2}{*}{ Pretreatment } & 15 & $\begin{array}{c}2 \cdot 17 \\
(0.90)\end{array}$ & $\begin{array}{c}2.23 \\
(0.71)\end{array}$ & $\begin{array}{c}1.45 \\
(0.62)\end{array}$ & $\begin{array}{c}3.63 \\
(0.99)\end{array}$ & $\begin{array}{l}1.82 \\
(0.95)\end{array}$ & $\begin{array}{l}60 \cdot 60 \\
(4 \cdot 60)\end{array}$ & $\begin{array}{c}8.98 \\
(1.45)\end{array}$ \\
\hline & & $P<0.01$ & $P<0.05$ & NS & $P<0.01$ & $P<0.01$ & $P<0.01$ & $P<0.01$ \\
\hline \multirow[t]{2}{*}{ At 2 weeks } & 15 & $\begin{array}{c}2 \cdot 89 \\
(0.84)\end{array}$ & $\begin{array}{c}2.32 \\
(0.66)\end{array}$ & $\begin{array}{c}1.28 \\
(0.63)\end{array}$ & $\begin{array}{l}1.47 \\
(0.85)\end{array}$ & $\begin{array}{c}3.40 \\
(1.03)\end{array}$ & $\begin{array}{l}90 \cdot 87 \\
(4 \cdot 45)\end{array}$ & $\begin{array}{l}11 \cdot 78 \\
(1.65)\end{array}$ \\
\hline & & NS & $P<0.05$ & NS & NS & NS & $P<0.01$ & $P<0.01$ \\
\hline
\end{tabular}

NS = not significant.

T A B L E I I I

MEAN VALUES (AND STANDARD DEVIATIONS) FOR PREDICTED NORMAL AND PATIENTS

\begin{tabular}{|c|c|c|c|c|c|c|c|c|}
\hline & \multirow[b]{2}{*}{ No. } & \multicolumn{7}{|c|}{ Lung Function Measurements } \\
\hline & & $\begin{array}{l}\text { VC } \\
\text { (1.) }\end{array}$ & $\underset{\text { (1.) }}{\text { FRC }}$ & $\begin{array}{l}\text { RV } \\
\text { (1.) }\end{array}$ & $\begin{array}{c}\text { TLC } \\
\text { (1.) }\end{array}$ & $\underset{(1 . / \mathrm{sec})}{\text { MMFR }}$ & $\underset{(1 . / \min )}{\text { FEV }_{0.75}} \times 40$ & $\underset{(\mathrm{ml} / \mathrm{min} / \mathrm{mmH})}{\mathrm{TF}}$ \\
\hline Predicted normal & 12 & $\begin{array}{c}3 \cdot 61 \\
(0 \cdot 73)\end{array}$ & $\begin{array}{c}3.05 \\
(0.64)\end{array}$ & $\begin{array}{l}1.52 \\
(0.51)\end{array}$ & $\begin{array}{l}4.98 \\
(0.84)\end{array}$ & $\begin{array}{c}4 \cdot 13 \\
(0.73)\end{array}$ & $\begin{array}{r}114.84 \\
(3.85)\end{array}$ & $\begin{array}{l}21.05 \\
(1.91)\end{array}$ \\
\hline \multirow[t]{2}{*}{ At 6 months } & 12 & $\begin{array}{c}2.96 \\
(0.87)\end{array}$ & $\begin{array}{c}2.43 \\
(0.67)\end{array}$ & $\begin{array}{c}1 \cdot 37 \\
(0 \cdot 70)\end{array}$ & $\begin{array}{c}4 \cdot 32 \\
(0.85)\end{array}$ & $\begin{array}{c}3 \cdot 69 \\
(1 \cdot 22)\end{array}$ & $\begin{array}{l}94 \cdot 92 \\
(4 \cdot 89)\end{array}$ & $\begin{array}{l}13 \cdot 70 \\
(2 \cdot 07)\end{array}$ \\
\hline & & NS & NS & NS & NS & NS & $P<0.01$ & $P<0.01$ \\
\hline Predicted normal & 15 & $\begin{array}{c}3.46 \\
(0.81)\end{array}$ & $\begin{array}{l}2 \cdot 85 \\
(0.74)\end{array}$ & $\begin{array}{c}1.43 \\
(0.53)\end{array}$ & $\begin{array}{c}4 \cdot 80 \\
(0 \cdot 88)\end{array}$ & $\begin{array}{l}4.04 \\
(0.78)\end{array}$ & $\begin{array}{l}111.33 \\
(4 \cdot 45)\end{array}$ & $\begin{array}{l}20 \cdot 46 \\
(2 \cdot 03)\end{array}$ \\
\hline \multirow[t]{2}{*}{ At 2 years } & 15 & $\begin{array}{c}3 \cdot 12 \\
(0.88)\end{array}$ & $\begin{array}{c}2 \cdot 39 \\
(0 \cdot 85)\end{array}$ & $\begin{array}{c}1 \cdot 34 \\
(0 \cdot 70)\end{array}$ & $\begin{array}{c}4.46 \\
(1.04)\end{array}$ & $\begin{array}{c}3 \cdot 51 \\
(1 \cdot 14)\end{array}$ & $\begin{array}{l}94 \cdot 00 \\
(4 \cdot 97)\end{array}$ & $\begin{array}{l}13.43 \\
(2.05)\end{array}$ \\
\hline & & NS & NS & NS & NS & NS & $P<0.01$ & $P<0.01$ \\
\hline
\end{tabular}

NS $=$ not significant. 


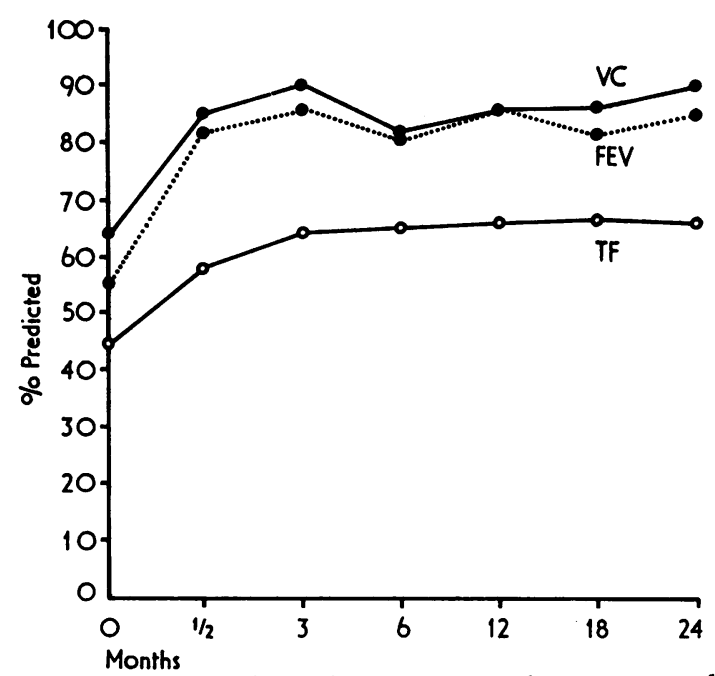

FIGURE Mean values of $V C, F E V$, and TF expressed as percentages of predicted values.

\section{DISCUSSION}

The follow-up lung function data reveal several features. The six patients with an obstructive and restrictive pattern were initially hypoxaemic. This hypoxaemia is likely to be due to impaired gas transfer in the lung as a result of airway obstruction and was corrected with relief of the obstruction.

For the group as a whole, the only significant persisting abnormalities were the decrease in transfer factor and the slight fall in forced expiratory volume. The latter could be due to the slightly reduced vital capacity. This result is at variance with those reported by Udwadia (1967), who stated that 'in those that did respond, return of lung function to normal levels was well nigh two and a half months after complete relief of symptoms'. However, he did not measure the transfer factor in his patients.

Previous studies by Udwadia and Joshi (1964) have shown that the pathological changes in the lung depend on the duration of the disease, 'the longer the duration of symptoms the greater the pulmonary fibrosis'. The 15 patients in this study have a mean duration of symptoms of $7 \cdot 4$ weeks with a range of one to 20 weeks. It would appear from the present data that this period is compatible with a return of function to normal except for the transfer factor. It is uncertain why some patients present with a superimposed reversible airway obstruction although it is likely that the type and extent of the lung reaction vary from one patient to another, depending on the immunological state.
There has been no report of the pathology of the lung in tropical pulmonary eosinophilia follow-듬 ing successful therapy with diethylcarbamazine other than the study of the two cases by Udwadia $\widetilde{\varnothing}$ and Joshi (1964). One of our patients successfully treated for tropical pulmonary eosinophilia and ${ }^{\text {s }}$ followed up for three years was subjected to. lung biopsy. This patient had repeated small $=$ attacks of haemoptysis following the onset of his illness. No cause could be found. He was not anaemic and at the time of his lung biopsy his lung function data were all normal except for $\mathrm{a}^{\mathrm{C}}$ low transfer factor $(60 \%$ of predicted). The histology was reported as follows: 'Sections show no granulomatous lesions or significant inflam-o matory reaction. There is very mild interstitial fibrosis - of doubtful significance. There is mild $z$ to moderate thickening of both pulmonary arteries? (medial and adventitial) and veins (adventitial) $;$ the arterial internal elastic lamina is fragmentedo and deficient in places'. While it is not possible to extrapolate this report to the state of the 150 patients (whose lung function data are similar $\rightarrow$ but who are, however, asymptomatic) it could bec postulated that a similar though less severe vas cular lesion and some mild interstitial fibrosis account for the low transfer factor. Further studyo is necessary to elicit the cause of this persistento defect.

I wish to thank Professor K. Shanmugaratnam, of the Department of Pathology, University of Singapore? for the histology report and Mr. C. W. Sam, of the. Ministry of Health, Singapore, for statistical assistance

\section{REFERENCES}

Azad Khan, A. K., Patra, R. W. T., Banu, S. A., and Rabbee, M. F. (1970). Spirometry in tropicaP Diseases of the Chest, 64, 107.

Nesarajah, M. S. (1972). Pulmonary function in tropical eosinophilia. Thorax, 27, 185.

Poh, S. C. (1973). Lung function in tropical pulmonary eosinophilia. 8th Proceedings of the SingaporeMalaysia Congress of Medicine. (In press.) and Chia, M. (1969). Respiratory function tests in normal adult Chinese in Singapore. Singaporew Medical Journal, 10, 265.

Udwadia, F. E. (1967). Tropical eosinophiliacorrelation of clinical, histopathologic and lung function studies. Diseases of the Chest, 52, 531. and Joshi, V. V. (1964). A study of tropicalo eosinophilia. Thorax, 19, 548.

Requests for reprints to: Dr. S. C. Poh, Tan Tock的 Seng Hospital, Singapore 11. 